\title{
EDITORIAL
}

\section{Could you imagine that much of images?}

\section{Você poderia imaginar essa quantidade de imagens?}

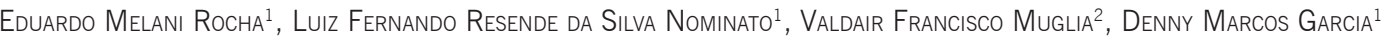

An individual's life or his/her entire medical history, from conception to death, may be documented as ultrasound images, radiographies, tomographies, photos, movies of surgical procedures, and measurable data converted into graphics illustrating descriptive and comparative statistics. Could anyone have predicted this 20 years ago?

This is possible and not only limited to ophthalmology. Most, if not all, medical areas are capturing, analyzing, and saving patient data from early development to senescence, and the information supporting this technology is growing day by day. New medical studies, addressing the issue of medical image technology in different areas, are being published. Recently launched medical journals are entirely dedicated to the science of medical image analysis. Moreover, major clinical medical journals have specific sections dedicated to diagnostic imaging ${ }^{(1)}$. What is the impact of this image revolution on modern medicine that is strongly affecting developments within ophthalmology?

Before a solution regarding portability and safe storage of all this information is available, there are three major concerns for daily practice in ophthalmology. To adapt to and survive in the image data avalanche, ophthalmologists are sometimes forced to make decisions on topics hardly covered by their skills and regular training, including security of digital data, decisions on treatment based on new and unique parameters, and communication of prognosis based on database comparisons and metadata analyses. Medical schools and residency programs will be required to prepare and teach trainees on how to wisely deal with these challenges.

Being one of the pioneers in the use and storage of diagnostic images, ophthalmology has a particular responsibility in this scenario, and over the past few years, it has been a leading medical specialty with regard to introducing equipment and generating image and/or digital analytical graphics to support diagnosis and disease outcomes (Table 1).

The first published human fundus photography was developed in 1886 by Jackman and Webster. At first, these images were quite blurry. However, improvements in instrumentation and technology enabled the use of fundus photography for clinical purposes in 1926 with the release of the first commercially available fundus camera by Carl Zeiss Company ${ }^{(2)}$. These retina images represented a major contribution in the management of diabetic retinopathy, infections, and neoplasias, among other diseases. Before that, and until recently, direct microscopy and color pencils were used in eye clinics worldwide to draw and illustrate vascular changes, perimetric fields, ocular surface changes, and other findings. These manual resources were standardized by reputed experts in ophthalmology, and although useful, they were very dependent on the skills, time, and patience of the observer/painter ${ }^{(3)}$.

Following fundus photography, the first member of the family and grandfather of the actual image eye center, generations of machines started to emerge in hospital departments and budgets, including ocular ultrasound modes A and B, corneal topography, and more recently, automatic visual field, multifocal electroretinography, GDX, and optical coherence tomography (OCT) (Table 1).

The clinical relevance of this image revolution can be summarized in few words: digital images and examination data in conjunction with automated comparison with databases encouraging the decision to treat. Protocols and guidelines are ultimately based on a unique parameter or its variation over a period of time, so as to support medical decisions. This is applicable to corneal endothelial cell counting, visual field mean deviation, macular retinal, and corneal thickness or curvature, just to mention a few ${ }^{(4-5)}$.

To prepare the clinic for a new season, pioneering ophthalmologists must be familiar with some specific terms and new technologies. It is necessary to plan ahead the future steps in terms of technology acquisition and to be ready for changes and expansion, without starting over after every new release. Here is some advice for ophthalmologists interested in the field (Table 2).

Submitted for publication: July 8,2015 Accepted for publication: July 17, 2015

Departamento de Oftalmologia, Otorrinolaringologia e Cirurgia de Cabeça e Pescoço, Faculdade de Medicina, Universidade de São Paulo (FMRP-USP), Ribeirão Preto, SP, Brazil.

Centro de Ciências da Imagem e Física Médica, Departamento de Clínica Médica, Faculdade de

Medicina, Universidade de São Paulo (FMRP-USP), Ribeirão Preto, SP, Brazil.
Funding: No specific financial support was available for this study.

Disclosure of potential conflicts of interest: None of the authors have any potential conflicts of interest to disclose.

Corresponding author: Eduardo Melani Rocha. Departamento de Oftalmologia, Otorrinolaringologia e Cirurgia de Cabeça e Pescoço, Faculdade de Medicina, Universidade de São Paulo (USP). Av. Bandeirantes, 3.900 - Ribeirão Preto - SP - 14049-900 - Brazil - E-mail: emrocha@fmrp.usp.br 
Health records need to be electronically stored and easily shareable in a secure manner. The following obstacles must be overcome to achieve this goal. The first is accessibility; to know where they are and how to access patient data. This requires the ability to store data in standard formats. Currently, the standard of reference for medical images is the Digital Imaging and Communications in Medicine (DICOM) format, which was created by the National Electrical Manufacturers Association, a North American organization, to improve distribution and viewing of medical images initially acquired using ultrasound, computed tomography, and magnetic resonance scanners. Nowadays, the DICOM format has gained wide acceptance in almost every medical field that uses images, including cardiology, gastroenterology, and ophthalmology. The major advantage of the DICOM format is that every file (image) not only has all information pertinent to any given particular examination but also maintains relevant patient data that is included in the header of scanners/devices, such as name, date of birth, and the institution's ID.

The second obstacle is to develop a stable and expansible database. Another important issue is privacy that ensures only authorized practitioners can access and extract information from stored records. For increased security, a method for verification of authenticity is required, along with integrity and authorship, which can be provided using a public key infrastructure encryption. Last, but not the least, remote accessibility maintaining privacy remains a challenging task because when one moves from the intranet to Internet, theoretically anyone can access such information. The use of a virtual private network is required to encrypt and protect data transmission.

It is possible to predict that in the future we may need to ask or recall less with regard to medical facts of individual patients because most, if not all, facts will be documented by images and digital files. Clinical histories will be stored in the patient's medical cloud, which will be accessible to the doctor in a display terminal, in the presence of or in remote contact with the patient to clarify and attend to specific requests. One can also assume that most routine tests and appointments will be automatically scheduled to keep individual files updated and to promote individual health in the best possible way.

Table 1. Data on digital equipment used in diagnostic ophthalmology, year of invention, and introduction in the clinical practice

\begin{tabular}{|c|c|c|c|c|c|}
\hline Equipment & Inventors & Invention & Clinical use* & Objective & Company \\
\hline Fundus photography & WT Jackman \& JD Webster & 1886 & 1926 & Observation of the fundus & Carl Zeiss \\
\hline Fluorescein angiography & HR Novotny \& DL Alvis & 1961 & & Observation of the retinal vasculature & \\
\hline Ultrasound mode $A$ and $B^{(6,7)}$ & Mundt \& Hughes & 1956 & 1958 & Ultrasonic ocular diagnosis & \\
\hline Corneal topography ${ }^{(9)}$ & Klyce & 1984 & 1987 & Observation of anterior corneal curvature & Computed Anatomy Inc \\
\hline Automated visual field & F Frankhauser & 1972 & 1976 & Visual field evaluation & Interzeag AG \\
\hline Electroretinography & J Dewar & 1877 & 1941 & Electric activity of retinal cells & \\
\hline$O C T^{(10)}$ & J Fujimoto & 1991 & 1996 & Histological analysis of the retina in vivo & Humphrey Systems \\
\hline Orbscan $^{(9)}$ & E. Sarver and C. Broadus & 1994 & 1995 & $\begin{array}{l}\text { Observation of the posterior } \\
\text { corneal curvature }\end{array}$ & Orbteck Inc. \\
\hline
\end{tabular}

* Year the technology began to be used in clinical practice.

Table 2. Tips for eye clinics interested in an efficient digital image storage and display system

\begin{tabular}{|c|c|c|}
\hline Item & Issue & Solution \\
\hline 1 & How to capture and store the information from the equipment & Digital Imaging and Communications in Medicine (DICOM) \\
\hline 2 & How to store accumulating digital data & $\begin{array}{l}\text { Cloud/picture archiving and communication system (PACS)/ } \\
\text { Health Insurance Portability and Accountability Act (HIPAA) }\end{array}$ \\
\hline 3 & How to protect patient privacy & Data encryption \\
\hline 4 & How to remotely transfer the information to the clinical file & Standard protocols accessing "cloud" by mobile apps. \\
\hline 5 & How to share patient information & XML tags \\
\hline
\end{tabular}

\section{REFERENCES}

1. Browse figures \& Multimedia. New Engl J Med [Internet]. [cited 2015 Jul 18]. Available from: http://www.nejm.org/multimedia/images-in-clinical-medicine

2. Saine PJ. Landmarks in the historical development of fluorescein angiography. J Ophthalmic Photogr. 1993;15(1):17-23.

3. Waring GO, Laibson PR. A systematic method of drawing corneal pathologic conditions. Arch Ophthalmol. 1977;95(9):1540-2.

4. Folgar FA, Jaffe GJ, Ying GS, Maguire MG, Toth CA; Comparison of Age-Related Macular Degeneration Treatments Trials Research Group. Comparison of optical coherence tomography assessments in the comparison of age-related macular degeneration treatments trials. Ophthalmology. 2014;121(10):1956-65. Collaborators: 893.

5. Wittig-Silva C, Chanb E, Islam FM, Wu T, Whiting M, Snibson GR. A randomized, con- trolled trial of corneal collagen cross-linking in progressive keratoconus: three-year results. Ophthalmology. 2014;121(4):812-21.

6. Mundt GH Jr, Hughes WF Jr. Ultrasonics in ocular diagnosis. Am J Ophthalmol. 1956; 421(3):488-98.

7. Baum G, Greenwood I. The application of ultrasonic locating techniques to ophthalmology. II. Ultrasonic slit-lamp in the ultrasonic visualization of soft tissues. Arch Ophthalmol.1958;60(2):263-79.

8. Maurice, D. A scanning slit optical microscope. Invest Ophthalmol. 1974;13(12):1033-7

9. Gutmark R, Guyton DL. Origins of the keratometer and its evolving role in ophthalmology. Surv Ophthalmol. 2010;55(5):481-97.

10. Huang D, Swanson EA, Lin CP, Schuman JS, Stinson WG, Chang W, et al. Optical coherence tomography. Science. 1991;254(5035):1178-81. 